\title{
Flexural behaviors analysis of ECC-RC composite beams reinforced with FRP bar based on OpenSees
}

\author{
GE Wenjie ${ }^{a *}$, Chen Junyu ${ }^{b}$, Wang Haihuan ${ }^{c}, Z_{\text {Zhao Ke }}^{d}$ \\ College of Civil Science Engineering, Yangzhou University, Yangzhou 225127, China \\ agewj@yzu.edu.cn, b978615302@qq.com, c1536165374@qq.com, d1455336515@qq.com
}

Keywords: FRP bars, concrete, ECC, composite beams, flexural behaviors

\begin{abstract}
Based on the finite element analysis software OpenSees, the flexural behaviors of ECC-RC composite beams reinforced with FRP bars is analyzed. The results show that cracking, yield and ultimate moment increase with the increasing of height replacement rate and the increasing rate slow down gradually. Yield and ultimate moment increase with the increasing of reinforcement ratio or reinforcement strength. The stiffness of ECC-RC composite beams reinforced with steel bars essentially unchanged after the cracking of ECC. Stiffness decreasing of ECC-RC composite beams reinforced with FRP bars is slower than RC beams reinforced with FRP bars after cracking.
\end{abstract}

\section{Introduction}

FRP bars is a kind of linear elastic material, it do not have yield platform which steel bars have, so the flexural failure of FRP reinforced concrete beams is brittle [1,2]. Design specifications and guidelines generally recommend that the FRP reinforced beam was designed into a super-reinforced beam which could use the plastic deformation of the concrete compression zone to obtain ductility member [3]. And the deflection and crack width of FRP RC beams are bigger than RC beams with the same reinforcement ratio, so the requirement of normal use limit state are often the controlling design factor of FRP beams. ECC (Engineered Cementitious Composite) overcome the softening performance of traditional cement-based material under tensile load, it exhibits similar pseudo-hardened characteristics like metal material, the single crack microscopic cracking development model of traditional cement based material change to multiple micro crack steady cracking models can be achieved, it has significant nonlinear deformation, excellent toughness and energy absorption capacity [4]. Maalej [5] propose using ECC in place part concrete which around the longitudinal tensile reinforcement and tested ECC reinforced RC composite beams. Research shows that compared with normal RC beams, ECC reinforced RC composite beam has a small increase in the bearing capacity and deformation capacity, but before steel yielding, crack width is less than $0.05 \mathrm{~mm}$, just normal RC beams' $1 / 5$. Feng [6] think that when the crack width is less than $0.05 \mathrm{~mm}$, impact of waterproof, anti-corrosion and weight bearing can be neglect. Therefore, the use of ECC can greatly improve the durability of concrete beams. Xu [7] made theoretical analysis of the flexural cracking behavior of reinforced ECC concrete composite beams, and made flexural test of 15 composite beams, the results show that using ECC can control crack width well, it can delay steel corrosion, improve the durability of the structure. Zhang [8] gives a simple method to evaluate flexural failure mode of high toughness cement-based composites beams.
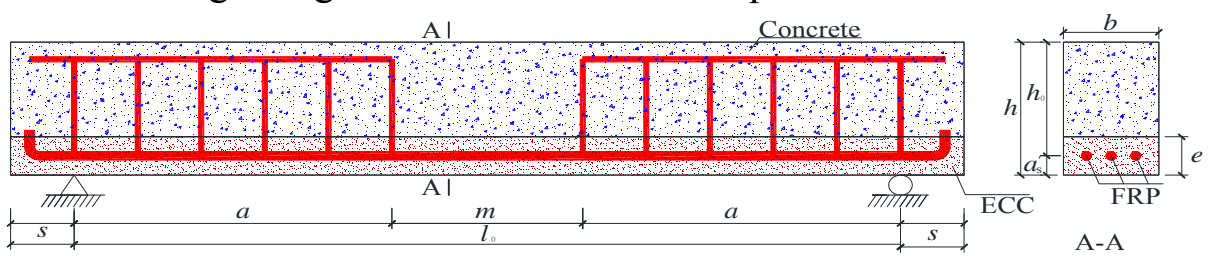

Fig.1 ECC-FRP reinforced concrete composite beam schematic diagram

Currently study are focused on the flexural behaviors of ECC beams reinforced with steel bars and ECC-RC composite beam reinforced with steel bars, and relatively study is still lack. Study on the flexural behaviors of ECC-RC composite beam reinforced with FRP bars (as shown in figure 1) has 
not been reported. Based on an open software system-OpenSees [9], the flexural behaviors of ECC-RC composite beam reinforced with FRP bars were analyzed.

\section{OpenSees Introduction}

OpenSees stands for Open System for Earthquake Engineering Simulation (Open System for Earthquake Engineering Simulation). It was funded by the National Natural Science Foundation (NSF), University of Western Union "Pacific Earthquake Engineering Research Center" (Pacific Earthquake Engineering Research Center, referred PEER) and university of California, Berkeley. It is an open software system that used to simulate seismic response of structure and geotechnical more comprehensively. OpenSees can be used to simple linear elastic static analysis, static nonlinear analysis, cross-sectional analysis, modal analysis, Pushover pseudo-dynamic analysis, dynamic linear elastic analysis and complex dynamic nonlinear analysis. Reinforced concrete structures simulation results of finite element analysis mainly depend on the accuracy of used material constitutive model. Steel01 material was used as the constitutive relationship of FRP bars and steel bars. Uniaxial concrete stress - strain model Concrete06 Material was used as the constitutive relationship of concrete and ECC material.

\section{Parameter Analyses}

Basic analysis parameters.Specimen size $b \times h \times l=150 \mathrm{~mm} \times 200 \mathrm{~mm} \times 1500 \mathrm{~mm}$. C35 fine aggregate concrete was used, protective layer thickness of longitudinal reinforcement is $20 \mathrm{~mm}, f_{c k}=23.4$ $\mathrm{N} / \mathrm{mm}^{2}, f_{\mathrm{c}}=16.7 \mathrm{~N} / \mathrm{mm}^{2}, f_{\mathrm{tk}}=2.2 \mathrm{~N} / \mathrm{mm}^{2}, f_{\mathrm{t}}=1.57 \mathrm{~N} / \mathrm{mm}^{2}, E_{\mathrm{c}}=31.5 \times 10^{3} \mathrm{~N} / \mathrm{mm}^{2}$. Diameter of $12 \mathrm{~mm}$ and $8 \mathrm{~mm}$ HRB400 steel bars were used as longitudinal reinforcement and stirrups respectively, $f_{\mathrm{yk}}=400$ $\mathrm{N} / \mathrm{mm}^{2}, E_{\mathrm{s}}=200 \times 10^{3} \mathrm{~N} / \mathrm{mm}^{2}$; Diameter of $8 \mathrm{~mm}$ basalt reinforced plastic bars was used, $f_{\mathrm{u}}=900$ $\mathrm{N} / \mathrm{mm}^{2}, E_{\mathrm{s}}=60 \times 10^{3} \mathrm{~N} / \mathrm{mm}^{2}$. Material strength standard values were adopted in the numerical simulation.

Table 1 Specimen parameters

\begin{tabular}{ccccc}
\hline NO. & longitudinal bars & stirrups & erection bar & $r_{\mathrm{h}}$ \\
\hline ESC & $1 \$ 12$ & $\$ 8 @ 250$ & $2 \$ 10$ & $0 / 0.25 / 0.5 / 0.75 / 1.0$ \\
ESE & $2 \$ 12$ & $\$ 8 @ 100$ & $2 \$ 10$ & $0 / 0.25 / 0.5 / 0.75 / 1.0$ \\
EFG & $1 \$ 8$ & $\$ 8 @ 250$ & $2 \$ 10$ & $0 / 0.25 / 0.5 / 0.75 / 1.0$ \\
EFH & $2 \$ 8$ & $\$ 8 @ 100$ & $2 \$ 10$ & $0 / 0.25 / 0.5 / 0.75 / 1.0$ \\
\hline
\end{tabular}

Note: $\$$, HRB400 steel; $\varnothing$, FRP bars; $r_{h}$, height replacement rate.

Cracking moment. The relationship curves of cracking moment and the height replacement rate are shown in figure 2. Cracking moment increases with the increasing of height replacement rate and the increasing rate gradually slow down. When $0 \leqslant r_{h} \leqslant 0.5$, it increases greatly; when $0.5<r_{\mathrm{h}} \leqslant 1.0$, increasing amplitude decreases. When $r_{\mathrm{h}}=1.0$, cracking moment of EFG group declines. Reinforcement ratio of EFG components is low, when $r_{\mathrm{h}}=1.0$, while ECC is cracking in the edge of tension, corresponding compression zone edge strain becomes lower, the neutral axis is moved up, the internal forces arm of the section is reduced, cracking moment then declines; cracking moment of group EFH is larger than group EFG, cracking moment of group ESE is larger than group ESC, cracking moment increases with the increasing of replacement ratio.

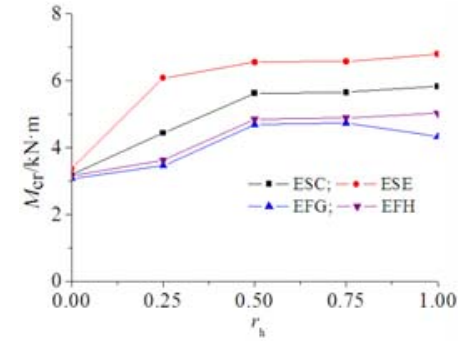

Fig.2 The curves of cracking moment and height replacement rate

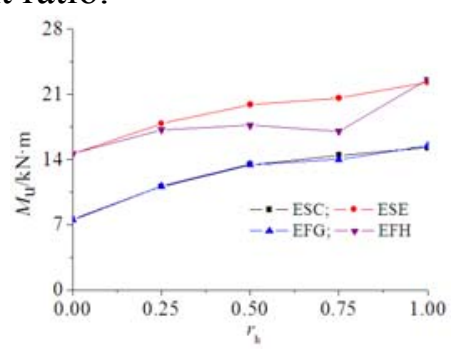

Fig.3 The curves of ultimate moment and height replacement rate 
Ultimate moment.The relationship curves of ultimate moment and the height replacement rate are shown in figure 3. Ultimate moment of group ESC, ESE, EFH increases with the increasing of height replacement rate and the increasing rate gradually slow down; For EFH group, when $0.25<r_{\mathrm{h}} \leqslant 0.75$, ultimate moment decreased, when $r_{\mathrm{h}}=0$, specimen failure modes is the breaking of FRP bars, when $r_{\mathrm{h}}=0.25,0.5$ and 0.75 , concrete crushed; When $r_{\mathrm{h}}=1.0$, specimen failure modes is the breaking of FRP bars. With the increasing of height replacement rate, when concrete was crushed, ECC strained in the tensile edge reduce, so the height of the internal forces arm of the section decreases, ultimate moment decreases; when specimen height replacement rates of ESC, ESH group are the same, specimen ultimate moments are closed, because the reinforcement strength are similar, that is $f_{\mathrm{y}} \mathrm{A}_{\mathrm{s}} \approx f_{\mathrm{u}} \mathrm{A}_{\mathrm{f}}$.

Mid-span load-deflection curves. Curves of mid-span moment and deflection are shown in figure 4.
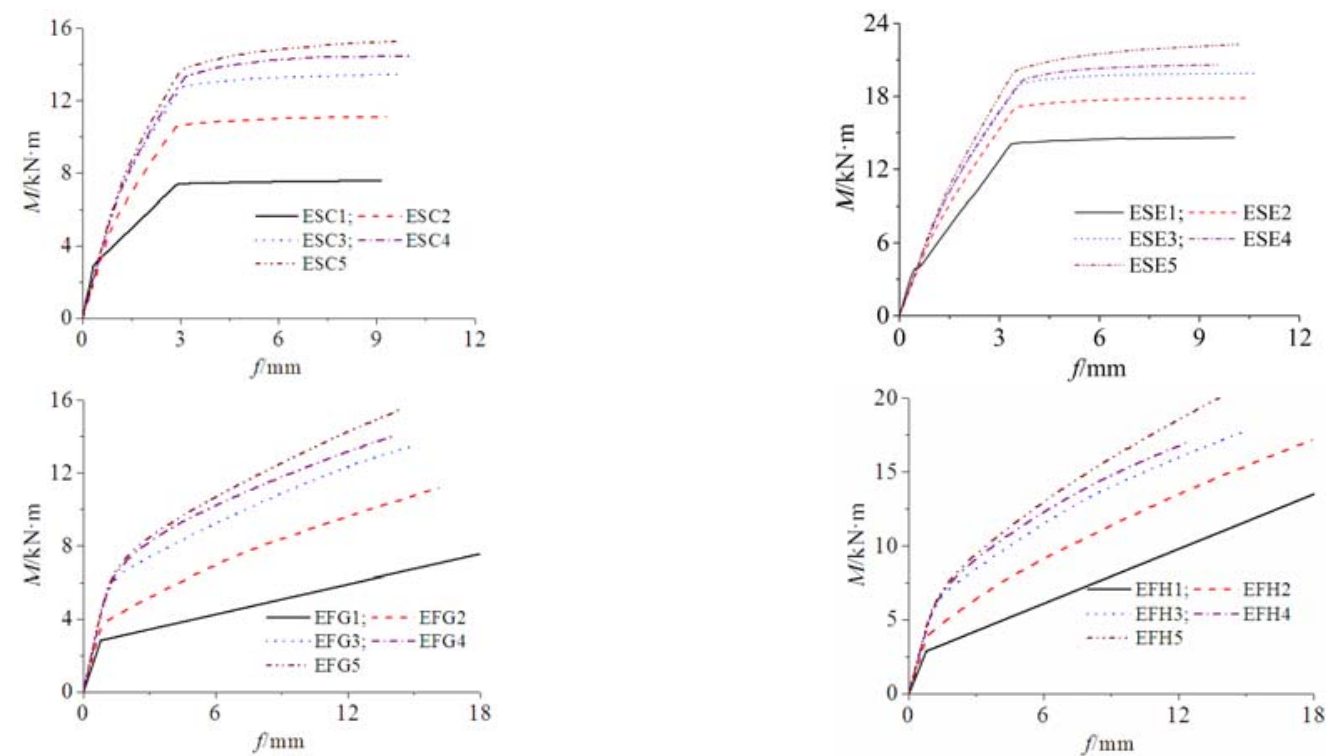

Fig.4 Specimen mid-span M-f curves

Load-deflection curves of composite beam (ESC, ESS) reinforced with steel bars can be divided into three stages. First, being loaded until ECC in the tension zone is cracking. Second, start from cracking to the yield of steel bars. After cracking, the stiffness of normal RC specimen decreases, while the stiffness of composite beams reinforced with steel bars nearly unchanged after the cracking of ECC. Third, from the yield of steel bars to the damage of specimen, the phenomena of composite beams is the same with reinforced concrete beam, specimen deflection increase greatly while the load is increased slightly. Depending on the strength grade, area of steel bars and the replacement rate, there are two composite beam failure modes, steel breaking or concrete crushing, specimen ESE3, ESE4 failure mode are concrete crushing, others specimen failure modes are steel breaking.

Load-deflection curves of composite beams reinforced with FRP bars can be divided into two sections. First, from begin loading to the yield of steel bars. After cracking, the stiffness of concrete beams reinforced with FRP bars decreases largely, while the stiffness of ECC-RC composite beams reinforced with FRP bars decreases slightly after the cracking of ECC. The failure mode of the specimen EFG4, EFH2, EFH3, EFH4 are concrete crushing, others specimen failure modes are the breaking of FRP bars. Because the reinforcement ratio is low, damage model of all ECC beams are the breaking of reinforced bars.

\section{Conclusions}

(1) Composite beam cracking moment increases with the increasing of height replacement rate and the increasing rate gradually slow down. With the same replacement height, cracking moment increases with the increasing of reinforcement ratio. 
(2) Ultimate moment of composite beams increases with the increasing of height replacement rate and the increase rate slow down gradually. Ultimate moment increases with the increasing of reinforcement ratio.

(3) The loading process of ECC-RC composite beams can be divided into three sections. First, being loaded until ECC is cracking. Second, from ECC is cracking to the steel is yield. After the cracking of ECC, stiffness of reinforced concrete specimens decreases while the stiffness of composite beam remained unchanged. Third, from steel is yield to the specimen is damaged, the deflection increase greatly while the load increases slightly.

(4) The load-deflection curves of ECC-RC composite beam reinforced with FRP bars can be divided into two sections. First, from begin loading to the yield of steel. After the cracking of concrete, the stiffness of concrete beams reinforced with FRP bars decreases largely while stiffness of the composite beams drops a little.

(5) With the different of the strength grade of materials, reinforcement ratio and height replacement rate, there are two failure modes of composite beams, reinforcement break or concrete crush. Because the reinforcement ratio is low, damage models of all ECC beams are the breaking of reinforced bars.

\section{Acknowledgments}

The authors appreciate the support of the national natural science foundation of China (51308490), the natural science foundation of Jiangsu province, China(BK20130450), the science and technology projects of ministry of housing and urban-rural development (2013-K4-17), the natural science foundation for colleges and universities in Jiangsu province (13KJB560015), the science and technology projects fund of Yangzhou city (2012149), the open foundation of southeast university, key laboratory of concrete and pre-stressed concrete structure of ministry of education, the Jiangsu government scholarship for overseas studies, Students' academic technology innovation fund project, Yangzhou university (x2015488).

\section{References}

[1] H. A. Abdulla. Evaluation of deflection in concrete members reinforced with fiber reinforced polymer (FRP) bars [J]. Composite Structures, 2002, 56(1): 63-71.

[2] Wenjie Ge, Jiwen Zhang, Dafu Cao, Yongming Tu. Flexural behaviors of hybrid concrete beams reinforced with BFRP bars and steel bars[J]. Construction and Building Materials, 2015(87): 28-37.

[3] Reported by ACI Committee ACI440. Guide for the Design and Construction of Concrete Reinforced with FRP Bars (ACI440.1R-03) [S]. Copyright, 2003.

[4] Li V C, Wang S, Wu C. Tensile strain-hardening behavior of PVA-ECC [J]. ACI Journal of Materials, 2001, 98(6): 483-492.

[5] Maalej, Li VC. Introduction of strain-hardening engineered cementitious composites in design of reinforced concrete flexural members for improved durability [J]. ACI Structural Journal, 1995, 92(2): 167-176.

[6] Naiqian Feng, Qingxia Gu, Tingyu Hao. Crack of concrete structure and Counter measures [M] Beijing: China Machine Press, 2006.

[7] Lang Xu, Nan Wang, Qinghua Li. Experimental study on the flexural performance of concrete beam strengthened with ultra high toughness cementitious composites [J]. China Civil Engineering Journal, 2010, 43 (5): 17-22.

[8] Yongxing Zhang. Simplified Evaluation Method on the Behavior of RC Member Strengthened by SHCC in flexural failure [J]. Engineering Fracture Mechanics, 2014, (121-122): 11-27. 
[9] Silvia Mazzoni, Frank MeKenna, Michael H Scott, Gregory L Fenves. OpenSees Example Manual [R]. PEER, University of California, Berkeley. 2003. 